\title{
Prone positioning in conscious patients on medical wards: A review of the evidence and its relevance to patients with COVID-19 infection
}

\author{
Authors: Thomas Chad ${ }^{A}$ and Caroline Sampson ${ }^{B}$
}

\begin{abstract}
Medical teams continue to treat many patients with COVID-19 infection. This disease can result in profound hypoxaemia that may necessitate intubation and invasive mechanical ventilation in those who are critically ill. This intervention carries risk to both patients and healthcare workers and utilises significant hospital resource for prolonged periods. Simple, safe interventions that can be used before critical deterioration are highly desirable. The prone position in conscious non-ventilated patients with COVID-19 infection may improve oxygenation in the short term and defer or prevent the need for intubation in some. However, clinicians must be aware that there is a small evidence base for this intervention currently. This review sets out evidence regarding the use of this technique to aid the decision making of frontline staff.
\end{abstract}

KEYWORDS: COVID-19, prone, acute respiratory failure, oxygenation, hypoxaemia

DOI: $10.7861 /$ clinmed.2020-0179

\section{Introduction}

The COVID-19 pandemic has transformed the way we practise inpatient medicine in a matter of weeks. The situation continues to evolve, and medical teams continue to manage a significant number of patients with confirmed or suspected infection.

COVID-19 infection can result in acute respiratory failure (ARF), with a significant minority meeting the criteria for acute respiratory distress syndrome (ARDS) and requiring admission to the intensive care unit (ICU). Early data from China suggested $3.4 \%$ developed ARDS and 5\% required ICU admission, ${ }^{1}$ although rates were higher within the Wuhan region, with $19.6 \%$ of 138 hospitalised patients developing ARDS and $26 \%$ requiring

Authors: Aacute care common stem/anaesthetics core trainee-1 doctor, University Hospitals of Leicester NHS Trust, Leicester, UK; ${ }^{B}$ consultant in critical care, anaesthesia and adult extra corporeal membrane oxygenation and deputy director for adult extra corporeal membrane oxygenation, University Hospitals of Leicester NHS Trust, Leicester, UK admission to the ICU. ${ }^{2}$ Those not treated in the ICU will be cared for by medical teams.

Many anecdotal therapies and treatment strategies have been reported by those caring for COVID-19 patients. One technique that has received interest, based on its simple mechanism of action and perceived low risk profile, is prone positioning in conscious non-ventilated patients. This rapid review highlights the theory and evidence base for this strategy with the hope of assisting frontline clinicians to decide if this technique could be of benefit to the patients they are treating.

\section{COVID-19, respiratory failure, ARDS and CARDS}

COVID-19 is a novel human infection and investigation of its pathophysiology is a rapidly evolving area of science. It causes a spectrum of disease with most hospitalised patients requiring admission for oxygen therapy ( $82 \%$ in one cohort). ${ }^{3}$ An acute respiratory failure may develop in those with pneumonia. This has been observed as marked hypoxaemia with a normal work of breathing in some. ${ }^{4}$ The mechanism for this is yet to be elucidated but is likely multifactorial. Lung compliance can remain normal in early disease. This may be due to oedema distributed to the interstitium rather than alveoli initially. ${ }^{5}$

In addition, there may be a failure of the normal hypoxic vasoconstriction mechanism secondary to endothelial dysfunction in areas of lung consolidation. ${ }^{6}$ This may also result in complementmediated coagulopathy: formation of microvascular pulmonary thrombi which further contributes to ventilation/perfusion $\left(\mathrm{V}_{\mathrm{a}} / \mathrm{Q}\right)$ mismatch and worsening respiratory failure. ${ }^{7}$ Pulmonary infiltrates tended to be bilateral $(79 \%)$, peripheral $(54 \%)$ or in the right lower lobe $(27 \%)^{8}{ }^{8}$

Many patients meet the 'Berlin criteria' for ARDS (summarised in Table 1). ${ }^{9}$ The ratio of partial pressure of arterial oxygen $\left(\mathrm{PaO}_{2}\right)$ to fraction of inspired oxygen $\left(\mathrm{FiO}_{2}\right)$ is used as a marker for the degree of hypoxaemia. Compared to COVID-19 patients who did not develop ARDS, those who did were older, had a higher fever on admission and were more likely to report dyspnoea. Bilirubin, urea and d-dimer were significantly higher and lymphocyte counts significantly lower. ${ }^{10}$ However, the Berlin definition of ARDS is extremely broad and does not reflect any single underlying pathology.

Some have suggested labelling ARDS in COVID-19 as 'atypical' ARDS or CARDS (COVID-19 with ARDS). ${ }^{5}$ Gattinoni et al have hypothesised a model of either 'L' or 'H' phenotypes. ' $L$ ' is typified by 
Table 1. The Berlin Criteria defining ARDS ${ }^{9}$

$\begin{array}{ll}\text { Timing } & \text { Within } 1 \text { week of either } 1) \text { clinical insult or } 2) \text { deterioration in respiratory symptoms } \\ \text { Imaging } & \text { Chest imaging reveals bilateral opacities not fully explained by effusions, lung collapse, nodules } \\ \text { Oedema } & \text { Respiratory failure not fully explained by pulmonary oedema secondary to cardiac failure } \\ \text { Oxygenation } & \text { Mild } \\ \text { Moderate } & \mathrm{PaO}_{2} / \mathrm{FiO}_{2} \leq 39.9 \mathrm{kPa}(\leq 300 \mathrm{mmHg}) \text { with PEEP or CPAP } \geq 5 \mathrm{cmH}_{2} \mathrm{O}\end{array}$

low lung elastance (high compliance), low $\mathrm{V}_{\mathrm{a}} / \mathrm{Q}$ ratio, low lung weight and low recruitability seen in early disease. Some patients progress to ' $H$ ': high elastance (low compliance), high right to left shunt, high lung weight and high recruitability, reflecting more 'typical' ARDS.11

This is still debated, given that progression from ' $\mathrm{l}$ ' to ' $\mathrm{H}$ ' phenotypes has not been documented clinically to date, and other data suggest that many 'atypical' features of CARDS (including preserved compliance) simply reflect existing heterogeneity in existing cohorts of ARDS patients. ${ }^{12}$ In addition, many have cautioned against diverting from established ventilation strategies in ventilated patients.

Intubation and invasive mechanical ventilation (IMV) may be an option in those critically ill with COVID-19; however, it may not be deemed appropriate for many patients. This may be due to a less severe respiratory failure or inappropriateness of escalation to ICU-level care. As the pandemic continues to develop worldwide, IMV may simply not be an option for many in resource-poor settings. Other strategies that can be employed before critical deterioration are therefore attractive.

\section{Oxygen therapy}

The mainstay of therapy in COVID-19 infection is optimising oxygen delivery. In response to anticipated high oxygen demand within hospitals, National Institute for Health and Care Excellence (NICE) guidance has recommended an adjustment to normal target $\mathrm{SpO}_{2}$ targets in all hospitalised patients (92-96\% in first instance, $90-94 \%$ if high overall oxygen flow demands). ${ }^{13}$ On medical wards oxygen is delivered via 'fixed' devices (Venturi or similar), achieving an $\mathrm{FiO}_{2}$ of $0.24-0.6$, or 'variable' devices (facemask \pm reservoir bag), achieving an $\mathrm{FiO}_{2}$ of 0.6-1.0. Continuous positive airway pressure (CPAP) and high flow nasal cannula (HFNC) devices can be used to enhance oxygen delivery.

CPAP delivers a constant positive pressure to the airways via an airtight mask or hood. It aims to deliver flow above that of a patient's peak inspiratory flow, maintaining the end expiratory airway pressure at a prescribed level (positive end expiratory pressure or PEEP, measured in $\mathrm{cmH}_{2} \mathrm{O}$ ). This increases mean airway pressure, prevents collapse of alveoli at end expiration and improves oxygenation. NICE has recently stated that 'CPAP is the preferred form of non-invasive ventilatory support in the management of the hypoxaemic COVID-19 patient. Its use does not replace IMV, but early application may provide a bridge to IMV'.14

HFNC circuits are becoming a more common sight on medical wards and are often initiated by critical care outreach teams. These deliver up to $60 \mathrm{~L} / \mathrm{min}$ of humidified, warmed and oxygenated flow into the upper respiratory tract via modified nasal cannula. Humidification and warming increases tolerability, augments secretion clearance and prevents airway dehydration. $\mathrm{An} \mathrm{FiO}_{2}$ of 1.0 may be achieved via oxygen flushing of the upper airways. This decreases dead space ventilation and acts as an 'anatomical oxygen reservoir..15 PEEP delivery via HFNC is variable $(3-5 \mathrm{mmHg})$ and depends on factors such as cannula fit into the nostrils and degree of mouth versus nose breathing. Currently 'the use of HFNO is not advocated in COVID-19 patients based on lack of efficacy, oxygen use and infection spread'. ${ }^{4}$

Given the above, CPAP is one potential therapy in those in whom simple oxygen therapy is not enough. However, CPAP (and HFNC) require equipment and specialist nursing and are categorised as aerosol generating procedures (AGPs), ${ }^{16}$ mandating use of appropriate personal protective equipment to minimise risk of airborne transmission to healthcare workers. ${ }^{17}$ In addition, application of PEEP to spontaneously breathing patients who exhibit respiratory distress may result in a phenomenon known as patient self-induced lung injury (P-SILI). Forceful inspiratory effort results in large transpulmonary pressure fluctuations (where the transpulmonary pressure is the difference between alveolar and pleural pressures). This exerts large shear forces in vulnerable lung tissue, increasing tissue stress and vessel permeability. 5.18

\section{The prone position}

Simply, this is when a patient is repositioned from the supine to lie on their front. An early report into using this technique to improve oxygenation in patients with acute respiratory failure included a single awake, non-intubated patient, where its use apparently 'deferred intubation'.19 Since then the technique is largely utilised as a 'rescue therapy' in mechanically ventilated patients with severe ARDS. The PROSEVA (Prone Positioning in Severe Acute Respiratory Distress Syndrome) randomised controlled trial reported an impressive mortality benefit in IMV patients with severe ARDS when this technique was used alongside lung protective ventilation ( $23.6 \%$ versus $41.0 \% 90$-day mortality, hazard ratio [HR] 0.44, 95\% confidence interval [CI] 0.29-0.67)..$^{20}$

A later Cochrane systematic review concluded there were mortality benefits in adult ventilated patients with ARDS, with pooled mortality from eight trials indicating a reduction from $47 \%$ to $42 \%$ (relative risk [RR] $0.90,95 \%$ CI $0.82-0.98$, quality of evidence 'very low'). Treatment with prone positioning for $>16$ hours/day resulted in a difference in mortality versus non-prone of 47 versus $36 \%$ (five trials, RR $0.7795 \%$ CI $0.61-0.99$, quality of evidence moderate). ${ }^{21}$ 
Given the established benefits of prone position in these patients, some have suggested that the benefit could extend to those with early COVID-19 disease on medical wards.

\section{The physiological viewpoint}

When patients lie supine, ventilation of the lung is not even. The weight of the heart and mediastinum causes compression atelectasis of underlying lung (left lower lobe). Also, ventral (non-dependent) alveoli distend more readily versus the relatively compressed dorsal alveoli. This is due to both gravity and the 'shape mismatch' of the triangular lung expanding within a spherical chest cavity on inspiration. ${ }^{22}$ This results in heterogenous distribution of transpulmonary pressures (thus ventilation) across a ventral-dorsal axis. ${ }^{23}$ The graduated non-cardiogenic pulmonary oedema in dependent regions seen in typical ARDS may exacerbate this.

Pulmonary perfusion across lung regions in the supine position is also heterogenous. It is greatest in dependent dorsal regions, which is partly due to gravity and partly to the effects of the vascular architecture in these regions. ${ }^{24} \mathrm{PEEP}$ exaggerates this gradient. Together these contribute to a $\mathrm{V}_{\mathrm{a}} / \mathrm{Q}$ mismatch which impacts on arterial oxygenation in the presence of ARF and ARDS.

When a patient is placed prone, this therefore has several effects. It reverses the compression atelectasis of the heart and mediastinum. It leads to more homogenous distribution of ventilation across the lung and minimises distending forces in ventral alveoli. ${ }^{24}$ Perfusion persists to the dorsal region, with some evidence suggesting a greater capacity for hypoxic vasoconstriction in ventrocranial regions. This may be due to higher production of nitric oxide (a potent vasodilator) in the endothelium of the dorsal lung which may modify the vasoconstrictive mechanism to hypoxia. ${ }^{24}$ Thus prone positioning reduces the relative shunt fraction significantly (around 30\%). ${ }^{23}$ Improvements in $\mathrm{PaO}_{2} / \mathrm{FiO}_{2}$ of $34-62 \%$ have been documented in a review of observational data, with a variable temporal response (a trend towards an immediate response within 30 minutes followed by a continued response up to 24 hours). ${ }^{24}$

In addition, drainage of secretions is also aided when prone, where material in the dorsal lung travels to open airways. This may explain a reduced incidence of ventilator-associated pneumonia (VAP) in the prone position. ${ }^{25}$ Improvements in thoraco-abdominal compliance, particularly in patients with higher BMIs, are also observed by removing the detrimental effect weight of the chest wall. ${ }^{24}$

\section{Evidence for the prone position in IMV patients with COVID-19}

In one single centre observational study from Wuhan, Pan et al utilised prone position in seven of 12 mechanically ventilated patients when the $\mathrm{PaO}_{2} / \mathrm{FiO}_{2}$ was persistently $<20.0 \mathrm{kPa}$. The $\mathrm{PaO}_{2} / \mathrm{FiO}_{2}$ increased from $16 \pm 8.1$ to $24.3 \pm 18.7 \mathrm{kPa}$ in prone ( $p=0.065$ but deemed 'clinically relevant'). The authors used a novel index for measuring lung recruitability and reported significantly increased recruitability among those where prone position was used $(p=0.02)$. However, three of these seven patients received extra corporeal membrane oxygenation (ECMO) support and outcome data were not provided. ${ }^{26}$

More recently a cohort study from America has described the management of 66 IMV patients with COVID-19. In this study, 31 patients underwent prone positioning (in response to $\mathrm{PaO}_{2}$ I $\mathrm{FiO}_{2}<26.6 \mathrm{kPa}$ ), with a mean of two 'sessions' over 72 hours. This improved $\mathrm{PaO}_{2} / \mathrm{FiO}_{2}$ and compliance from median values of $20 \mathrm{kPa}$ and $33 \mathrm{ml} / \mathrm{cmH}_{2} \mathrm{O}$ (interquartile ranges [IQR] of 125-183 and $24-46$ ) to $31.1 \mathrm{kPa}$ and $35 \mathrm{ml} / \mathrm{cmH}_{2} \mathrm{O}$ (IQR $167-265$ and 34-47), which was similar to the response seen in non-COVID-19 ARDS patients. ${ }^{12}$ Interestingly only $85 \%(n=56)$ met the Berlin criteria for ARDS despite intubation.

The Surviving Sepsis campaign advocates for a trial of prone positioning in mechanically ventilated patients who meet the moderate to severe ARDS definition. ${ }^{27}$ They recommend periods of 12-16 hours, reflecting existing evidence for non-COVID ARDS.

The emergence of prone teams has been witnessed during this pandemic, with a heightened interest in utilising this technique for COVID-19 with ARDS. NHS England suggesting use of proning teams to 'improve efficiency' of instigating the technique. ${ }^{28}$

\section{Evidence for the prone position in conscious, non-ventilated COVID-19 patients}

Given the above, it is plausible that the underlying mechanism leading to improvement in oxygenation is analogous between invasively ventilated ICU patients with severe ARDS and nonventilated ward patients. A small number of reports have emerged and are summarised in Table 2.

Caputo et al, 2020. ${ }^{29}$ Consecutive adult patients presenting to a single centre with hypoxia $\left(\mathrm{SpO}_{2}<90 \%\right)$ who failed to respond to supplemental oxygen ( $\mathrm{SpO}_{2}$ to $>93 \%$ ) and who were able to selfprone were enrolled. 18 patients required intubation within 48 hours of admission ( $36 \%$ total). 12 participants were kept on nasal cannula pre-prone positioning, despite failure to achieve $\mathrm{SpO}_{2}>90 \%$.

Elharrar et al, 2020.30 Inclusion criteria included COVID-19. positive status, presence of posterior lesions on chest CT and an oxygen requirement, and exclusion criteria included requirement of immediate intubation or reduced consciousness. Only $28 \%$ of 88 consecutive patients met these criteria. It is unclear if patients that responded were treated with HFNC and/or tolerated prone positioning for longest. After 10 day follow up five participants were intubated.

Sartini et al, 2020. ${ }^{31}$ Here an opportunistic cross-sectional survey was conducted on a single day. Patients with ARDS secondary to COVID-19 who were already undergoing prone positioning in combination with CPAP outside of the ICU were analysed. Improvement was sustained after returning to supine and stopping CPAP in 12 participants when measured at the 1-hour mark. However, a selection bias is implicit in the study design. Interestingly, around half of participants had a $\mathrm{PaO}_{2} / \mathrm{FiO}_{2}$ $\leq 70 \mathrm{mmHg}$ prior to prone positioning, which appears critically low in spontaneously breathing patients a median of 5 days into treatment with prone + CPAP.

The Intensive Care Society have recently advocated for a trial of prone positioning in conscious patients with suspected/confirmed COVID-19 and $\mathrm{FiO}_{2}$ of $\geq 28 \%$ to maintain $\mathrm{SpO}_{2}$ 92-96\% (or $88-92 \%$ in those at risk of hypercapnic respiratory failure) despite basic respiratory support. They suggest utilising cycles of 30 minutes to 2 hours, rotating through prone to right sided to supine to left sided positioning. ${ }^{32}$ Pre-pandemic data were referenced here.

\section{Pre-pandemic evidence for conscious prone positioning}

Several key trials conducted before the emergence of COVID-19 are summarised in Table 3. 
Table 2. Summary of reports into conscious prone positioning in COVID-19 patients

\begin{tabular}{|c|c|c|c|c|c|c|c|}
\hline Authors & $\mathrm{n}$ & $\begin{array}{l}\text { Intervention } \\
\text { (respiratory } \\
\text { device) }\end{array}$ & Setting & Outcome & Key results & Strengths & Limitations \\
\hline $\begin{array}{l}\text { Caputo et al, } \\
2020^{29}\end{array}$ & 50 & $\begin{array}{l}\text { Single episode of } \\
\text { prone position for } \\
5 \text { minutes } \\
\text { (Non-rebreathe } \\
\text { mask or nasal } \\
\text { cannula) }\end{array}$ & ED (ARF) & $\begin{array}{l}\text { Improvement in } \\
\mathrm{SpO}_{2} \text { from supine } \\
\text { to prone }\end{array}$ & $\begin{array}{l}\mathrm{SpO}_{2} \text { increased } \\
\text { from } 84 \% \text { to } 94 \% * \\
\left(\mathrm{FiO}_{2} \text { not altered }\right)\end{array}$ & $\begin{array}{l}\text { Proves feasibility } \\
\text { in acute setting } \\
\text { Prone positioning } \\
\text { was only } \\
\text { intervention }\end{array}$ & $\begin{array}{l}\text { Oxygen delivery } \\
\text { not optimised } \\
\text { before intervention } \\
\text { Short prone } \\
\text { episode }\end{array}$ \\
\hline $\begin{array}{l}\text { Elharrar et al, } \\
2020^{30}\end{array}$ & 24 & $\begin{array}{l}\text { Single episode of } \\
\text { prone positioning } \\
\text { for as long as } \\
\text { tolerated }^{+} \\
\text {(Nasal cannula } \\
n=16 \text {, facemask/ } \\
\text { HFNC } n=8 \text { ) }\end{array}$ & $\begin{array}{l}\text { Non-ICU } \\
\text { (ARF) }\end{array}$ & $\begin{array}{l}\text { Increase in } \mathrm{PaO}_{2} \\
\text { of } \geq 20 \% \text { when } \\
\text { in prone position }\end{array}$ & $\begin{array}{l}\text { Six responded } \\
\left(\mathrm{PaO}_{2} 9.8 \text { to } 12.5\right. \\
\mathrm{kPa}, 95 \% \mathrm{CI} \\
0.8-4.8)^{\ddagger}\end{array}$ & $\begin{array}{l}\text { Measured } \\
\text { response to } \\
\text { re-supination } \\
\text { 10-day follow up }\end{array}$ & $\begin{array}{l}\text { Only } 28 \% \text { met } \\
\text { inclusion criteria } \\
\text { Unclear who } \\
\text { received HFNC } \\
\text { Variable length } \\
\text { of intervention }\end{array}$ \\
\hline $\begin{array}{l}\text { Sartini et al, } \\
2020^{31}\end{array}$ & 15 & $\begin{array}{l}\text { Evaluation of all } \\
\text { prone episodes } \\
\text { on a single day } \\
\text { (duration of } \\
\text { episodes } 3 \text { hours, } \\
\text { IQR 1-6) } \\
\text { (CPAP while in } \\
\text { prone position) }\end{array}$ & $\begin{array}{l}\text { Non-ICU } \\
\text { (ARDS) }\end{array}$ & $\begin{array}{l}\text { Change in } \mathrm{RR} \text {, } \\
\mathrm{SpO}_{2} \text { and } \mathrm{PaO}_{2} / \\
\mathrm{FiO}_{2} \text { when in } \\
\text { prone position }\end{array}$ & $\begin{array}{l}\text { All had } \\
\text { significantly } \\
\text { improved } \mathrm{SpO}_{2} \\
\text { and } \mathrm{PaO}_{2} / \mathrm{FiO}_{2} \\
\text { during prone } \\
\text { position }\end{array}$ & $\begin{array}{l}\text { Proves feasibility } \\
14 \text {-day follow up }\end{array}$ & $\begin{array}{l}\text { Interventions } \\
\text { combined } \\
\text { Patients already } \\
\text { receiving } \\
\text { intervention for } \\
\text { median } 5 \text { days } \\
\text { prior } \\
\text { Patients not } \\
\text { included if had } \\
\text { failed intervention } \\
\text { prior to day of } \\
\text { data collection }\end{array}$ \\
\hline
\end{tabular}

ARF = acute respiratory failure; $\mathrm{CPAP}=$ continuous positive airway pressure; $\mathrm{ED}=$ emergency department; $\mathrm{HFNC}=$ high flow nasal cannula; ICU = intensive care unit; $\mathrm{RR}=$ respiratory rate. ${ }^{*} \mathrm{p}=0.001$. ${ }^{+}$Four patients tolerating $<1$ hour, 15 tolerating for $>3$ hours. ${ }^{*}$ Three participants maintained response when returned to supine. ${ }^{5} \mathrm{p}<0.001$; however, exact figures not supplied.

Scaravilli et al, 2015. ${ }^{33} 13$ had a diagnosis of pneumonia and 5 had a pre-existing diagnosis of COPD. Any improvements in those who were maintained on facemasks only is not reported separately. Oxygen mask use fell on prone positioning from $56 \%$ pre prone positioning to $37 \%$ during prone positioning across all 43 prone episodes; the effect of HFNC/CPAP likely contributed to the difference seen.

Ding et al, 2020.34 20 patients with pneumonia (influenza in $45 \%$ ) were diagnosed with ARDS on a trial of PEEP $5 \mathrm{cmH}_{2} \mathrm{O}$ via CPAP/BiPAP (10 moderate, 10 severe). Patients then moved from HFNC, to HFNC + prone, to CPAP/BiPAP, to CPAP/BiPAP + prone to IMV if the target $\mathrm{SpO}_{2}$ of $>90 \%$ could not be maintained. 11 avoided intubation (success group), where the largest increase in $\mathrm{PaO}_{2} / \mathrm{FiO}_{2}$ was seen between $\mathrm{HFNC}$ to HFNC + prone (Table 3 ). Only one patient in the success group did not progress to requiring NIV based on their protocol, and a significant improvement in $\mathrm{PaO}_{2} / \mathrm{FiO}_{2}$ was also seen between HFNC + prone to NIV $(131 \pm 38,156 \pm 36, p=0.046)$. The retrospective separation of the success and failure overstates these benefits, although the success group did have significantly higher $\mathrm{PaO}_{2} / \mathrm{FiO}_{2}$ at baseline possibly indicating benefit in less severe disease.
Valter et al, 2003. ${ }^{35}$ Four cases of hypoxaemic respiratory failure secondary to pneumonia are reported. BiPAP/CPAP were used preprone positioning in three patients, which was de-escalated in all three post prone positioning. One patient died in this group (of a cerebral infarct 18 days later).

Bellone and Basile, 2018. ${ }^{36}$ Three cases of acute respiratory failure secondary to unspecified pneumonia were followed over 9 days. Prone positioning was started due to lack of response to a combination of HFNC and BiPAP over the first 48 hours of admission. A continued improvement to repeated episodes of prone positioning with HFNC was seen over the following 7 days and all patients were discharged from hospital.

\section{Safety}

Most safety data are of low quality, and almost exclusively derived from intubated patients. Here the pooled adverse event profile (seven studies, $>7000$ patients) indicated an RR of 1.10 (1.01 to 1.2), (quality of evidence deemed 'very low'). Without the concern for dislodgement of tracheal tube in conscious, non-intubated patients, the main safety issues are development of pressure sores (face, sternum in particular) and loss of venous access. ${ }^{37}$ 
Table 3. Summary of the evidence for conscious prone positioning prior to the COVID-19 pandemic

\begin{tabular}{|c|c|c|c|c|c|c|c|}
\hline Authors & $\mathbf{n}$ & $\begin{array}{l}\text { Intervention } \\
\text { (respiratory } \\
\text { device) }\end{array}$ & Setting & Outcome & Key results & Strengths & Limitations \\
\hline $\begin{array}{l}\text { Scaravilli et al, } \\
2015^{33}\end{array}$ & 15 & $\begin{array}{l}\text { Prone episodes, } \\
1-3 \text { per } \\
\text { patient with } \\
\text { duration } 2-4 \\
\text { hours (longest } \\
8 \text { hours) } \\
\text { (Oxygen } \\
\text { facemasks, CPAP } \\
\text { and HFNC) }\end{array}$ & $\begin{array}{l}\text { ICU } \\
\text { (ARDS) }\end{array}$ & $\begin{array}{l}\text { Change in } \mathrm{PaO}_{2} / \\
\mathrm{FiO}_{2} \text { from supine } \\
\text { to prone position, } \\
\text { then return to } \\
\text { supine }\end{array}$ & $\begin{array}{l}\mathrm{PaO}_{2} / \mathrm{FiO}_{2}(\mathrm{kPa}) \\
11.9 \pm 3.7 \text { to } \\
16.5 \pm 7.1^{*} \\
\text { (returning to } \\
12.1 \pm 5.6)^{*}\end{array}$ & $\begin{array}{l}\text { Measured } \\
\text { response to } \\
\text { re-supination } \\
\text { after } 6-8 \text { hours }\end{array}$ & $\begin{array}{l}\text { Respiratory device } \\
\text { the same over } \\
\text { prone episode in } \\
\text { only } 18 / 43\end{array}$ \\
\hline $\begin{array}{l}\text { Ding et al, } \\
2020^{34}\end{array}$ & 20 & $\begin{array}{l}\text { Protocolised } \\
\text { trials of HFNC } \\
\text { or CPAP/BiPAP } \\
+/- \text { prone } \\
\text { positioning }\end{array}$ & $\begin{array}{l}\text { ICU } \\
\text { (ARDS) }\end{array}$ & $\begin{array}{l}\text { Intubation rate } \\
\text { Change in } \mathrm{PaO}_{2} / \\
\mathrm{FiO}_{2} \text { from supine } \\
\text { to prone position }\end{array}$ & $\begin{array}{l}55 \% \text { intubated } \\
\text { (expected } 75 \% \text { ) } \\
\mathrm{PaO}_{2} / \mathrm{FiO}_{2}(\mathrm{kPa}) \\
12.7 \pm 2.9 \text { to } \\
17.3 \pm 4.7 \\
\mathrm{kPa}^{+} \text {(those } \\
\text { who avoided } \\
\text { intubation) }\end{array}$ & $\begin{array}{l}\text { Meaningful } \\
\text { primary outcome } \\
\text { Suggests benefit } \\
\text { in moderate } \\
\text { ARDS or varying } \\
\text { aetiology }\end{array}$ & $\begin{array}{l}\text { Complex protocol } \\
\text { with combination } \\
\text { of interventions } \\
\text { unachievable on } \\
\text { wards } \\
\text { Results for success } \\
\text { and failure } \\
\text { groups reported } \\
\text { separately }\end{array}$ \\
\hline $\begin{array}{l}\text { Valter et al, } \\
2003^{35}\end{array}$ & 4 & $\begin{array}{l}\text { Single episode } \\
\text { of prone } \\
\text { positioning, } \\
\text { duration } 50 \\
\text { minutes to } \\
5 \text { hours } \\
\text { (CPAP/BiPAP } \\
\text { used pre-prone } \\
\text { positioning in } \\
n=3 \text { ) }\end{array}$ & ICU (ARF) & $\begin{array}{l}\text { Change in } \mathrm{PaO}_{2} / \\
\mathrm{FiO}_{2} \text { from supine } \\
\text { to prone position }\end{array}$ & $\begin{array}{l}\mathrm{PaO}_{2} / \mathrm{FiO}_{2}(\mathrm{kPa}) \\
11.9 \text { to } 24.7 \\
\text { (mean values) }\end{array}$ & & Small case series \\
\hline $\begin{array}{l}\text { Bellone and } \\
\text { Basile, } 2018^{36}\end{array}$ & 3 & $\begin{array}{l}\text { Repeated } \\
\text { episodes of prone } \\
\text { positioning for } \\
6 \text { hrs/day (HFNC } \\
\text { during prone } \\
\text { positioning) }\end{array}$ & $\begin{array}{l}\text { Emergency } \\
\text { ward (ARF) }\end{array}$ & $\begin{array}{l}\text { Change in } \mathrm{PaO}_{2} / \\
\mathrm{FiO}_{2} \text { from supine } \\
\text { to prone position }\end{array}$ & $\begin{array}{l}\mathrm{PaO}_{2} / \mathrm{FiO}_{2} \\
(\mathrm{kPa}) 15.7 \text { to } \\
36.7 \text { ( } 1 \text { day of } \\
\text { intervention) to } \\
40.4 \text { ( } 9 \text { days of } \\
\text { intervention }\end{array}$ & $\begin{array}{l}\text { Suggests } \\
\text { improvement } \\
\text { with sustained } \\
\text { use of prone } \\
\text { positioning }\end{array}$ & Small case series \\
\hline
\end{tabular}

ARF = acute respiratory failure; BiPAP = bilevel positive airway pressure; $\mathrm{CPAP}=$ continuous positive airway pressure; $\mathrm{ED}=$ emergency department; $\mathrm{HFNC}=$ high flow nasal cannula; ICU $=$ intensive care unit. ${ }^{*} p<0.05$ from preceding intervention. ${ }^{\dagger} p=0.016$, HFNC to HFNC + prone.

There was a low rate of intolerance to the prone position (2/43 total prone procedures), with no other adverse events noted previously. ${ }^{33}$ However, the safety profile of this technique on the general medical ward is unknown. The risk of aspiration in obtunded patients, for example, would have more severe consequences in those without a protected airway. Table 4 outlines contraindications for use of this technique in ward patients as outlined by the Intensive Care Society UK. ${ }^{32}$

\section{Conclusion}

Current evidence for conscious prone positioning in both ARDS and ARF is of low quality. Most reports have had small sample sizes, lacked controls, displayed incomplete data (particularly regarding outcome), used variable intervention length and combined therapies (prone positioning with HFNC or CPAP). This severely limits the ability to draw firm inferences about the potential benefit of prone positioning as the sole intervention in patients with ARF secondary to COVID-19.

However, short term improvements in oxygenation are seen, which may reflect the intervention acting simply as a 'recruitment manoeuvre'. This may help to avoid or defer intubation in a selected group with less severe disease. It is unclear if short term improvements in oxygenation would translate into a similar mortality benefit to that seen with prolonged periods of prone positioning utilised in IMV patients with severe ARDS.

There is certainly a physiological rationale for investigating this intervention further both in the setting of COVID-19 (with 
Table 4. Examples of relative contraindications to the prone position in awake, non-invasively ventilated patients on medical wards. Adapted from ICS (2020) $)^{32}$

\author{
Absolute contraindications \\ Respiratory distress \\ Immediate need for intubation \\ Haemodynamically unstable \\ Agitation or altered mental state \\ Unstable spine/thoracic injury/recent abdominal surgery \\ Relative contraindications \\ Facial injury \\ Neurological issues \\ Morbid obesity \\ Pregnancy \\ Pressure sores
}

\section{Additional considerations}

$\mathrm{RR}>35, \mathrm{PCO}_{2} \geq 6.5 \mathrm{kPa}$, accessory muscle use

$\mathrm{SBP}<90 \mathrm{mmHg}$, arrythmia

$\mathrm{PCO}_{2}=$ partial pressure carbon dioxide; $\mathrm{RR}=$ respiratory rate; $\mathrm{SBP}=$ systolic blood pressure.

several clinical trials registered on clinicaltrials.org: NCT04350723, NCT04358939, NCT04344587 and NCT04366856) and beyond.

The intervention is achievable on medical wards and appears safe.

\section{References}

1 Guan W, Ni Z, Hu Y et al. Clinical characteristics of coronavirus disease 2019 in China. N Engl J Med 2020;382:1708-20.

2 Wang D, Hu B, Hu C et al. Clinical characteristics of 138 hospitalized patients with 2019 novel coronavirus-infected pneumonia in Wuhan, China. JAMA 2020;323:1061-9.

3 Yang $X, Y u, Y, X u$ J et al. Clinical course and outcomes of critically ill patients with SARS-CoV-2 pneumonia in Wuhan, China: a single-centered, retrospective, observational study. Lancet Respir Med 2020;8:475-81.

4 Xie J, Tong Z, Guan X et al. Critical care crisis and some recommendations during the COVID-19 epidemic in China. Intensive Care Med 2020;46:837-40.

5 Marini ] and Gattinoni L. Management of COVID-19 respiratory distress. JAMA 2020, in press (doi: 10.1001/jama.2020.6825).

6 Min Lang M, Som A, Mendoza D et al. Hypoxaemia related to COVID-19: vascular and perfusion abnormalities on dual-energy CT. Lancet Infect Dis 2020, in press (doi: 10.1016/S1473-3099 (20)30367-4).

7 Ciceri F, Beretta L, Scandroglio A et al. Microvascular COVID-19 lung vessels obstructive thromboinflammatory syndrome (MicroCLOTS): an atypical acute respiratory distress syndrome working hypothesis. Crit Care Resusc 2020, in press.

8 Shi $\mathrm{H}$, Han $\mathrm{X}$, Jiang $\mathrm{N}$ et al. Radiological findings from 81 patients with COVID-19 pneumonia in Wuhan, China: a descriptive study. Lancet Infect Dis 2020;20:425-34.

9 The ARDS Definition Task Force. Acute respiratory distress syndrome: the Berlin definition. JAMA 2012;307:2526-33.

10 Wu C, Chen X, Cai Y et al. Risk factors associated with acute respiratory distress syndrome and death in patients with coronavirus disease 2019 pneumonia in Wuhan, China. JAMA Intern Med 2020, in press (doi: 10.1001/jamainternmed.2020.0994).

11 Gattinoni L, Chiumello d, Caironi P et al. COVID-19 pneumonia: different respiratory treatment for different phenotypes? Intensive Care Med 2020, in press (doi: 10.1007/s00134-020-06033-2).
12 Ziehr D, Alladina J, Petri C et al. Respiratory pathophysiology of mechanically ventilated patients with COVID-19: a cohort study. Am J Respir Crit Care Med 2020, in press (doi: 10.1164/rccm.2020041163LE).

13 National Institute for Health and Care Excellence. Clinical guide for the optimal use of oxygen therapy during the coronavirus pandemic. NICE, 2020. Available at www.england.nhs.uk/ coronavirus/wp-content/uploads/sites/52/2020/04/C0256specialty-guide-oxygen-therapy-and-coronavirus-9-april-2020.pdf [Accessed 9 April 2020].

14 National Institute for Health and Care Excellence. Guidance for the role and use of non-invasive respiratory support in adult patients with COVID19 (confirmed or suspected). NICE, 2020. Available at www.england.nhs.uk/coronavirus/wp-content/ uploads/sites/52/2020/03/specialty-guide-NIV-respiratorysupport-and-coronavirus-v3.pdf [Accessed 1 April 2020].

15 Ashraf-Kashani N, Kumar R. High-flow nasal oxygen therapy. BJA Education 2017:17:57-62.

16 Public Health England. Guidance COVID-19 personal protective equipment (PPE). PHE, 2020. Available at www.gov.uk/ government/publications/wuhan-novel-coronavirus-infectionprevention-and-control/covid-19-personal-protective-equipmentppe [Accessed 2 May 2020].

17 Ferioli M, Cisternino C, Leo V et al. Protecting healthcare workers from SARS-CoV-2 infection: practical indications. Eur Respir ] 2020;29:200068.

18 Grieco D, Menga L, Eleuteri D et al. Patient self-inflicted lung injury: implications for acute hypoxemic respiratory failure and ARDS patients on non-invasive support. Minerva Anestesiol 2019;85:1014-23.

19 Douglas W, Rehder K, Beynen F, Sessler A, Marsh H. Improved oxygenation in patients with acute respiratory failure: the prone position. Am Rev Respir Dis 1977;115:559-66.

20 Guérin C, Reignier J, Richard J-C et al. Prone positioning in severe acute respiratory distress syndrome. NEJM 2013;368:2159-68.

21 Bloomfield R, Noble D, Sudlow A. Prone position for acute respiratory failure in adults. Cochrane Database Systematic Rev 2015;11:CD008095.

22 Gattinoni L, Busana M, Giosa L, Macrì M, Quintel M. Prone positioning in acute respiratory distress syndrome. Semin Resp Crit Care 2019;40:94-100. 
23 Scholten E, Beitler J, Prisk G, Malhotra A. Treatment of ARDS with prone positioning. Chest 2017;151:215-24.

24 Kallet R. A comprehensive review of prone position in ARDS. Respiratory Care 2015;60:1660-87.

25 Li Bassi G, Torres A. Ventilator-associated pneumonia: role of positioning. Curr Opin Crit Care 2011;17:57-63.

26 Pan C, Chen L, Lu C et al. Lung recruitability in SARS-CoV-2 associated acute respiratory distress syndrome: a single-center, observational study. Am J Respir Crit Care Med 2020;201:1294-7.

27 Alhazzani W, Møller MH, Arabi YM et al. Surviving Sepsis Campaign: guidelines on the management of critically ill adults with coronavirus disease 2019 (COVID-19). Intensive Care Med 2020:46:854-887.

28 NHS England. Clinical guide for the management of critical care patients during the coronavirus pandemic. NHSE, 2020. Available at www.england.nhs.uk/coronavirus/wp-content/uploads/ sites/52/2020/03/specialty-guide-itu-and-coronavirus-v1-16-march2020.pdf [Accessed 2 May 2020].

29 Caputo N, Strayer R, Levitan R. Early self-proning in awake, non-intubated patients in the emergency department: a single ED's experience during the COVID-19 pandemic. Acad Emerg Med 27:375-8.

30 Elharrar $X$, Trigui $Y$, Dols A et al. Use of prone positioning in nonintubated patients with COVID-19 and hypoxemic acute respiratory failure. JAMA 2020, in press (doi: 10.1001/jama.2020.8255).

31 Sartini C, Tresoldi M, Scarpellini P et al. Respiratory parameters in patients with COVID-19 after using noninvasive ventilation in the prone position outside the intensive care unit. JAMA 2020, in press (doi: 10.1001/jama.2020.7861)
32 Intensive Care Society. ICS Guidance for prone positioning of the conscious COVID patient. ICS, 2020. Available at www.ics.ac.uk/ ICS/COVID-19/COVID-19_Guidance/ICS/GuidelinesAndStandards/ COVID19_Guidance.aspx?hkey=fff229b8-28da-43f6-a0d6-f2d50b5fcf68 [Accessed 2 May 2020].

33 Scaravilli V, Grasselli G, Castagna L et al. Prone positioning improves oxygenation in spontaneously breathing nonintubated patients with hypoxemic acute respiratory failure: A retrospective study. J Crit Care 2015;30:1390-4.

34 Ding L, Wang L, Ma W, He H. Efficacy and safety of early prone positioning combined with HFNC or NIV in moderate to severe ARDS: a multi-center prospective cohort study. Crit Care 2020; 24:28.

35 Valter C, Christensen A, Tollund C, Schønemann N. Response to the prone position in spontaneously breathing patients with hypoxemic respiratory failure. Acta Anaesthesiol Scand 2003;47:416-8.

36 Bellone A, Basile A. Prone positioning in severe acute hypoxemic respiratory failure in the emergency ward. Emerg Care J 2018; 14:22-3.

37 Faculty of Intensive Care Medicine. Guidelines on the management of acute respiratory distress syndrome. FICM, 2018. Available from www.ficm.ac.uk/sites/default/files/ficm_ics_ards_guideline_-_july_ 2018.pdf [Accessed 1 April 2020]

Address for correspondence: Dr Thomas Chad, Leicester Royal Infirmary, Infirmary Square, Leicester LE1 5WW, UK.

Email: tom.chad@doctors.org.uk 